\title{
Erratum to: Stepping Stones Triple P: An RCT of a Parenting Program with Parents of a Child Diagnosed with an Autism Spectrum Disorder
}

\author{
Koa Whittingham • Kate Sofronoff • Jeanie Sheffield • \\ Matthew R. Sanders
}

Published online: 29 August 2014

(C) Springer Science+Business Media New York 2014

\section{Erratum to: J Abnorm Child Psychol \\ DOI 10.1007/s10802-008-9285-x}

\begin{abstract}
Authors' Statement of Conflict of Interest The Triple P - Positive Parenting Program is owned by the University of Queensland. The University through its main technology transfer company, UniQuest Pty Ltd, has licensed Triple P International Pty Ltd to publish and disseminate the program worldwide. Royalties stemming from published Triple P resources are distributed in accordance with the University's intellectual property policy and flow to the Parenting and Family Support Centre; School of Psychology; Faculty of Health and Behavioural Sciences; and contributory authors. No author has any share or ownership in Triple P International Pty Ltd. Matthew Sanders is the founder and an author on various Triple $\mathrm{P}$ programs and a consultant to Triple $\mathrm{P}$ International. Koa Whittingham is a postdoctoral fellow at the University of Queensland; Kate Sofronoff and Jeanie Sheffield are academics on staff in the School of Psychology at the University of Queensland.
\end{abstract}

The online version of the original article can be found at http://dx.doi.org/ 10.1007/s10802-008-9285-x.

K. Whittingham $\cdot$ K. Sofronoff $(\bowtie) \cdot J$. Sheffield $\cdot$ M. R. Sanders

School of Psychology, The University of Queensland, St Lucia,

Brisbane, QLD 4072, Australia

e-mail: kate@psy.uq.edu.au 